\title{
Giant Solid Cerebellar Hemangioblastoma-En Bloc Resection without Preoperative Embolization
}

\author{
Narayanam Anantha Sai Kiran ${ }^{1}$ Veldurti Ananta Kiran Kumar ${ }^{1} \quad$ Valluri Anil Kumar ${ }^{2}$ Amit Agrawal ${ }^{1}$
}

${ }^{1}$ Department of Neurosurgery, Narayana Medical College Hospital, Nellore, Andhra Pradesh, India

2Department of Neuroanaesthesia, Narayana Medical College Hospital, Nellore, Andhra Pradesh, India

Indian J Neurosurg 2019;8:147-148

Giant solid cerebellar hemangioblastomas are rare lesions. Surgery is the treatment of choice for these highly vascular lesions, and preoperative embolization helps in reducing the blood loss during surgery. ${ }^{1}$ We describe a case of giant solid cerebellar hemangioblastoma that was excised en bloc without preoperative embolization.

A 45-year-old woman presented with history of headache, vomiting, and gait ataxia. Neurologic examination was normal except for cerebellar ataxia. Magnetic resonance imaging (MRI) ( Fig. 1A, B) revealed a large cerebellar lesion of size $3.6 \times 3 \times 2.2 \mathrm{~cm}$, which was hyperintense on T2weighted images with multiple flow voids inside the lesion (-Fig. 1A, B) and isointense on T1-weighted images. Tonsillar herniation was also noted. With the above imaging findings, possibility of giant solid cerebellar hemangioblastoma was considered. Preoperative digital subtraction angiography (DSA) and embolization could not be done due to financial constraints. Midline suboccipital craniectomy and complete excision of the lesion were done. Large highly vascular midline cerebellar lesion was circumferentially dissected. All the feeders to the lesion were gently coagulated and cut. Lesion was excised en bloc (-Fig. 1C) with minimal blood loss ( 600 mL). Postoperatively the patient was intact neurologically. Postoperative computed tomographic (CT) was normal. Biopsy was suggestive of hemangioblastoma. MRI at 3 months follow-up did not reveal any residual lesion. The
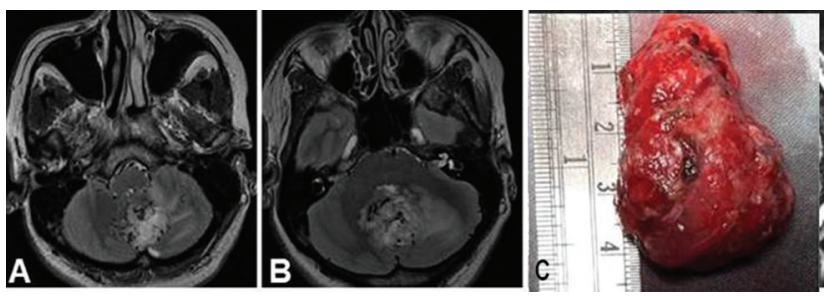

Fig. 1 (A, B) Axial T2-weighted images showing a large cerebellar vermian hyperintense lesion with multiple flow voids. (C) En bloc resected specimen.
Address for correspondence Narayanam Anantha Sai Kiran, MCh, Department of Neurosurgery, Narayana Medical College Hospital, Chinthareddy Palem, Nellore 524003, Andhra Pradesh, India (e-mail: sainarayanam1977@gmail.com).

patient was asymptomatic, except for pseudomeningocele, which was managed conservatively.

Surgery for giant solid cerebellar hemangioblastomas is technically challenging as surgery for these lesions can be associated with massive blood loss, and circumferential dissection for en bloc resection of such huge lesions is difficult. ${ }^{1}$ Sultan et al, in their series of 10 patients, reported preoperative total or near-total endovascular occlusion of giant solid cerebellar hemangioblastomas in $90 \%$ (9/10) of cases and successful resection even piece meal rather than en bloc resection with minimal blood loss. ${ }^{1}$ As blood supply to these lesions is from critical vessels such as posterior inferior cerebellar artery (PICA), risk of vertebrobasilar infarction from thromboembolic events during endovascular embolization exist. ${ }^{2}$ A high complication rate of $11.7 \%$ following preoperative embolization of intracranial hemangioblastomas was reported in a systematic review. ${ }^{2}$ To overcome the limitations of endovascular embolization, a technique of direct transcranial puncture of lesion under angiographic guidance and injection of onyx followed by successful resection has been reported. ${ }^{3}$ Radiosurgery for solid hemangioblastomas is limited to smaller lesions $(<3 \mathrm{~cm})$ which cannot be resected. ${ }^{4}$ Considering the complications associated with preoperative embolization and high cost involved in these procedures, en bloc excision of giant solid cerebellar hemangioblastomas is a reasonably safe option.

Source(s) of Support

None.

Presentation at a Meeting

None.

Conflicts of Interest

None.

Acknowledgment

None. published online August 28, 2019
DOI https://doi.org/ $10.1055 / \mathrm{s}-0039-1695085$ ISSN 2277-954X.
(C2019 Neurological Surgeons' Society of India
License terms

(®) $\Theta \circledast$ 


\section{References}

1 Sultan A, Hassan T, Aboul-Enein H, Mansour O, Ibrahim T. The value of preoperative embolization in large and giant solid cerebellar hemangioblastomas. Interv Neuroradiol 2016;22(4):482-488

2 Ampie L, Choy W, Lamano JB, et al. Safety and outcomes of preoperative embolization of intracranial hemangioblastomas: a systematic review. Clin Neurol Neurosurg 2016;150:143-151
3 Ding D, Starke RM, Evans AJ, Liu KC. Direct transcranial puncture for onyx embolization of a cerebellar hemangioblastoma. J Clin Neurosci 2014;21(6):1040-1043

4 Asthagiri AR, Mehta GU, Zach L, et al. Prospective evaluation of radiosurgery for hemangioblastomas in von Hippel-Lindau disease. Neuro-oncol 2010;12(1):80-86 